\title{
Internal Communication in Global Project Teams
}

\author{
MARTIN BIZJAK \\ University of Primorska, Slovenia \\ martin.bizjak87@gmail.com \\ ARMAND FAGANEL \\ University of Primorska, Slovenia \\ armand.faganel@upr.si
}

Communication in global project teams is emerging research topic as more and more work is done in form of global project, with geographically dispersed teams communicating using different communication channels. There are several unique dimensions to consider in comparison to communication in traditional project teams, including some unique risks and success factors. This article provides a systematic literature review on internal communication in global project teams. Cultural aspects of global project team collaboration were also investigated. A bibliometric analysis was performed through methodological approach applied in previous studies. Traditional project management and communication methods are not the best option for global projects as they can't answer the additional challenges that global projects provide in comparison to traditional projects. Key risks and success factors on global projects were identified and proposals extracted on how to run the internal communication on global projects. Requirements for successful global project manager were described. Our research revealed a gap in available literature, encouraging further exploration and serving as a basis for further research.

Key words: project management communication, global project management, internal communication, cultural impact, project performance, literature review

(cc)BY-SA https://doi.org/10.26493/1854-4231.15.179-206

\section{Introduction}

The field of project management rapidly expands as the global trend of projects is rising. The globalization of markets, mergers of international companies, and integration of managerial and business processes in global corporations are changing project management fundamentals (Eriksson et al. 2002). Project management practices are 
becoming increasingly important, as more and more work is organised through projects and programmes (Winter et al. 2006). Business activities are becoming more and more project based rather than process based (Zein 2012). Project management has long been considered as an academic field for planning-oriented techniques and an application of engineering science and optimization theory. Project management is now the dominant model in many organisations for strategy implementation, business transformation, continuous improvement and new product development. Due to rapid expansion the need for an internal discussion and debate about project management research increases (Söderlund 2004).

Binder (2009) wrote that project managers spend most of their time communicating. Effective communication to all stakeholders is according to Project Management Institute (2013) the most crucial success factor in project management with $55 \%$ of project managers agreeing on that. While communication could be seen as a traditional team issue, the problem is magnified by distance, cultural diversity and language or accent difficulties (Lee-Kelley and Sankey 2008).

The studied field is highly topical, since many authors discuss various aspects of project management and communication within teams all across the globe (e.g. Akkermans et al. 2020; Chen et al. 2019; Holzmann and Mazzini 2020; Kerzner 2019; Kock et al. 2020; Papadaki et al. 2019; Peña and Muñoz 2020; Shirley 2020; Souza, Tereso, and Mesquita 2020). The aim of the research is to investigate the process and role of internal communication in global project teams, distinguishing from internal communication in traditional project teams and emphasize the importance of cultural aspect in global project team communication. A literature review was performed with the focus on topics under investigation. The conclusions were drawn along with recommendation for further research in this area of science.

\section{Research Method}

Literature review process represents much more than collecting and summarizing literature (Onwuegbuzie et al. 2012). It is as a data collection tool, a method, a mixed research method, and, above all, a methodology (Onwuegbuzie and Frels 2016). The literature review represents a method as the literature reviewer chooses from an array of strategies and procedures for identifying, recording, understanding, meaning-making, and transmitting information pertinent to a topic of interest.

In the first step of our research we defined our research problem. 
According to Onwuegbuzie and Frels (2016), an effective problem statement is the description of a current and important challenge that is confronted by researchers and/or practitioners for which there are no adequate solutions available from the extant literature. We also defined research scope and boundaries (Mossolly 2015). In this research we decided to investigate what has been addressed in available literature about communication on projects, with special focus on internal communication in global project teams. Cultural impact was also investigated since it influences internal project communication, especially on global projects (Lee-Kelley and Sankey 2008). Several related contents such as communication with external stakeholders, vertical organizational communication, political and financial aspects of global project management were not discussed.

The search for literature was mostly done online, using academic databases such as ScienceDirect, ResearchGate and Emerald Insight and search engines such as Google and Google Scholar. The keywords 'project management communication,' 'global project management communication' and 'project management internal communication' were used to search for relevant literature as they obviously relate to the topic under research. Initial selection was done based on relevance of article titles for the topic under research. All the articles which passed through the first selection were carefully read and relevance for the topic under research was put under question again. Only articles identified as relevant for the topic under research were considered in this study. We categorized the literature under investigation based on its specific focus to help us structure the work, link the content and generate conclusions. The search was focused on the literature published in last decade; nevertheless, we still included some earlier publications which are found relevant for our research. Our literature review is a mixed research study as the primary studies under investigation were both qualitative and quantitative.

\section{Literature Review}

The major findings identified in reviewed literature, relevant for the topic under research, are confronted in this chapter. It starts with introduction of global projects and the differences to traditional projects. Requirements for global project manager are also discussed. Next chapter discusses the role and process of internal communication within global project team and the communication channels used. Last chapter focuses on cultural impact, including 
cultural management in global project teams. The specifics of some most important cultural entities are also explained.

\section{GLOBAL PROJECTS}

The definition of global projects is far from being obvious (Mossolly 2015). Among several other definitions, Fossum et al. (2019) define global projects as temporary collaborations between organizations across locational, temporal and relational distances with the intention to jointly deliver a unique product or service. Traditional projects are in contrast usually run within same organization and are not geographically dispersed. Another thing that distinguishes global projects from traditional is project complexity. Global projects are usually considered as high complexity projects, thus managing global projects using traditional project management approach would be difficult, or even impossible (Aarseth, Rolstadås, and Andersen 2013). Alami (2016) agrees that traditional project implementation is not an excellent fit for global projects.

\section{Differences to Traditional Projects}

One of several attributes distinguishing global from traditional projects are their unique risks. Both traditional and global project are subjected to certain level of risk, but comparing to traditional, the risks on global projects are usually higher. Caldas and Gupta (2017) observed that risk factors such as complexity, size and duration, contribute to several projects not achieving their performance objectives. There are several factors impacting global project complexity, Binder (2007) lists number of distant locations, different organizations, country cultures, different languages and time zones. Although many believe that project complexity reduces project management performance, the researchers so far failed to establish this causal relationship (Bjorvatn and Wald 2018). Another risk, common for both types of projects is lack of project management maturity, which affects the project success (Dube and Katane 2017). Aarseth, Rolstadås, and Andersen (2103) mention lack of organizational support, improper facing with external requirements and managing internal stakeholders in the project team as further risks the project team need to handle. Oertig and Buergi (2006) warn about the issue of high turnover in project teams. There are some risks, which are unique for global projects and mainly include political, economic and cultural risks ( $\mathrm{Li}$ 2009). Among these, political risk is believed to be the most difficult to mitigate. Eriksson et al. (2002) warn about the risk of local issues, which might prevail on global project, and even minor 
issues can become huge problems. Lack of mutual trust is also common risk on global projects and main issue of cooperation between people of different cultures (Anantatmula and Thomas 2008). Relational communication and psychosocial factors such as trust, commitment and communication have an important role in the functioning of global teams (Henttonen and Blomqvist 2005), but global team communication doesn't enable face-to-face communication, which cultivates trust and shared understandings (Alami 2016). Jarvenpaa and Leidner (1999) observe that global virtual teams may experience a form of 'swift' trust, but such trust appears to be very fragile and temporal. Still the trust must prevail within the team in order to achieve a high level of cooperation (Kalyvas 2009). There are number of different forms of trust and an optimal level of trust should be achieved to mitigate the chance of groupthink occurrence and to ensure a connection between trust, risk and interdependence within relationships (Parker, Kunde, and Zeppetella 2017). The project team needs to start with risk management activities from the very beginning of project. Clear requirement engineering from earliest stage of the project, as Eriksson et al. (2002) suggest, reduces costs and minimizes risk for misunderstandings. They also see prompt information availability for all team members on all organizational levels as another step towards successful project. To summarize, successful risk management on project is only possible through effective communication.

Beside risks it is also important to discuss global projects' success factors. Much research has been carried out to identify success factors in traditional projects, but little work has focused on success factors in global projects (Aarseth, Rolstadås, and Andersen 2013). One of key success factors on both traditional and global projects is timely change management, requiring fast and efficient communication for quick detection of deviations and timely decision making (Ahuja, Yang, and Shankar 2010). Collyer (2016) agrees that it is necessary to communicate fast and timely. Proctor and Doukakis (2003) see effective communication as crucial for successful introduction of the change. It ensures stakeholder participation in the change management processes through teamwork and empowerment, meanwhile lack of communication routines leads to straightforward project culture with task performance and efficiency preferred over stakeholder involvement (Butt, Naaranoja, and Savolainen 2016). Collyer (2016) suggests that managers faced with rapid change may benefit from a culture supporting efficient communication and flexible leadership with rapid decision making. They should also look beyond 
traditional tools of communication as these don't meet requirements for timely change management on global projects (Ahuja, Yang, and Shankar, 2010). Still, Oertig and Buergi (2006) encourage traditional face-to-face communication and relationship building, as it increases employee satisfaction (Men 2014) and mutual trust (Alami 2016). Eriksson et al. (2002) emphasize that it is important to create trust and commitment within the team. Mohd and Noraini (2012) also observe strong relation between communication and trust in determining team success, while Kalyvas (2009) agrees that these two are key success factors. Dube and Katane (2017) list organizational culture, leadership, trust, communication and team commitment as other important success factors, followed by project management maturity Proper selection of project management approach, either prescriptive or adaptive, can also be a success factor on project (Rolstadås et al. 2014). According to Lee-Kelley and Sankey (2008), the key success factors on global projects are project management competency, appropriate use of technology and networking ability, willingness for self-management, cultural and interpersonal awareness. Ranf (2010) adds sincere intention to integrate in new, different culture as the key to success in international business.

\section{Global Project Management Requirements}

Management of global project requires a project manager whose abilities reach further than what is usually required on traditional projects. Kalyvas (2009) observed that he or she needs to possess special abilities and skills comparing to those necessary for the traditional project manager. He or she has to deal with a number of challenges that require a flexible style of management, the ability to understand and a global mind-set, the ability to deal with the different cultural aspects, geographical distance, conflicts and tensions, communication, language, religion, customs, values and mutual trust (Lima and Patah 2016). He or she should be ready to face specific challenges, such as cross-cultural communication, work with different organizations, skewed time zones, multi-languages and collaboration across locations (Binder 2009). Being a good team builder and able to detect the strong points of his team is also necessary, besides strong understanding of the other people diversity and its acceptance (Kalyvas 2009). Project manager on global projects needs to be relationship-oriented and build trust to a much larger extent than in simpler projects (Aarseth, Rolstadås, and Andersen 2013). Bristol and Yeatts (2010) emphasize that style awareness, communication style flexibility and respecting humanity of others build trust 
within the team. Ambiguity acceptance and translation skills are two further requirements that project manager needs to fulfill (Gray and Ulbrich 2017). Browne et al. (2016) see communication skills as most important leadership attribute. Project manager does not communicate with language only, but also with character - attitude, behaviour and personality (Zulch 2014b). The project manager that is trusted by the team and gets them to work together will communicate successfully (Zulch 2014b). He or she must lead the global team effectively by communicating efficiently via the means of communication that are available today (Kalyvas 2009). Ranf (2010) adds that the project manager needs to understand his or her own culture and the cultures of the project stakeholders. Oertig and Buergi (2006) also emphasize the importance of selecting creative leaders with a collaborative leadership style and excellent communication skills. Fluency in both technical and leadership languages is required. Technical language helps to define outcomes, just as leadership language serves to create trust, manage conflicts, invite commitment, and embrace accountability while producing the right results. Successful project managers need to have both project management and leadership skills (Project Management Institute 2013). Kerzner (2009) adds that to be effective, a project manager should be aware of communication styles of others. Effective team leaders are social architects who understand the interaction of organizational and behavioural variables and can foster a climate of active participation, accountability and result-orientation. This requires excellent understanding of the business environment and its cultures, combined with sophisticated project management and leadership skills (Thamhain 2012). Management of global projects requires leaders with access and ability of transition between different departments of the company, in order to promote the means of interaction within the team, to stimulate intercultural learning and implement training programs to help develop the mind-set (Rodrigues and Sbragia 2013). Oertig and Buergi (2006) appreciate the investment in language and intercultural communication training, as communication is a skill, and it must be developed through education and practice (Zulch 2014b). Success is no longer the result of a few geniuses, but depends on effective multidisciplinary efforts, involving the team and other stakeholders interacting in a highly complex, intricate, and sometimes even chaotic way (Thamhain 2012). The list of project manager competencies is getting more and more extensive, which makes it hard to extract the core competencies only. Authors observe growing focus on soft competencies, but also the need of an update on project 
management education to fill the gap between education and the real world (Alvarenga et al. 2019).

INTERNAL COMMUNICATION IN GLOBAL PROJECT TEAMS

There are vast differences between communication on traditional and on global projects. The role of communication in global projects is even more important than in traditional due to their specific properties and requirements. Zajac (2013) sees project team communication as increasingly relevant research topic because the companies do more and more work in form of projects. Rodrigues and Sbragia (2013) also detect increasing trend of global projects and multicultural project teams, while Mossoly (2015) identifies the demand for special skills and knowledge required for managing global projects, raising the interest of researchers in this area.

\section{The Role and the Process of Communication in Global Project Teams}

Communication is as a core competency and connects project team members to common set of strategies, goals and actions. Although it is mostly viewed as the proper and timely delivery of information, it is more than that - the way that project managers generate the grounds for a project (Ziek and Anderson 2015). It could be defined as the function that integrates cost, scope and time to achieve a quality product and may be seen as having a foundation function (Zulch 2014a). Tkalac Verčič, Verčič, and Sriramesh (2012) define internal communication as an interdisciplinary function integrating elements of human resources management, communication and marketing. Most of the tasks performed by members of global teams are communicative and language-related (Zajac 2012). Communication is a key project manager's skill that has an impact on other cornerstone areas of project management (Men and Yue 2019). It must be delivered in a way that ensures effective participation of team members in order to achieve high team performance (Sarhadi, Yousefi, and Zamani 2018). Effective internal communication is crucial for successful organisations as it affects the ability of managers to engage employees and achieve objectives (Welch and Jackson 2007), moreover it is important integral part of employee development practice and one of the core elements of implementing employee development (Proctor and Doukakis 2003). It is also an important concept and integral to internal public relations with links to positive organizational and employee outcomes such as employee engagement (Karanges et al. 2015). It contributes to positive internal relation- 
ships by enabling horizontal communication between managers and employees, but can also pose a threat to organisational relationships, as poor communication can be counter-productive. Project managers who allow the team to take responsibility for their work will attain more from team members and communication will be more effective (Zulch 2014b). According to FitzPatrick (1997), effective communication of entire project team is the condition to have successful communication. Understanding the needs of different stakeholders, their motivations and interests is crucial for project managers (FitzPatrick 1997), as they are the key to the successful communication management (Curtin and Jones 2001). Project team members need to constantly collaborate, share, collate and integrate information and knowledge in order to realise project objectives (Zulch 2014b). Global project managers must involve the team members to identify the stakeholders and understand the communication channels between the team members. Having this in mind, good communication strategy must be defined (Binder 2009). Even if the project manager is the central point through which communications usually flow, the team members also need to be effective in their interactions with the stakeholders. To ensure this, the entire team needs to understand the goals, objectives, outcomes and benefits of the project (Cervone 2014). Sarhadi, Yousefi, and Zamani (2018) suggest that in modern paradigm, centralized power has taken a coordinator role in project teams by establishing a communication bottleneck, but in the participation paradigm, information flows freely among all project team members. Focused power is therefore replaced with effective communication. Stare (2011) on the other hand argues that increase of project manager authority positively impacts on several cultural dimensions and has a direct impact on the project's performance. Allen, Lee, and Tushman (1980) suggest that research projects show the best performances when they are not dominated by any individual, while technical projects perform better when the manager is more dominant and internal communication more structured.

In practice, communication process usually does not run smoothly and provides a constant challenge to project team members, especially to project management. Several organizations are facing problems with communication on projects and only one in four organizations can be described as highly-effective communicators, as Project Management Institute (2013) reveal. They further inform us that approximately two in five projects do not meet their original goals and business intent, and one of those is related to ineffective communication. There are several problems attributed to communication 
(Molena and Rovai 2016) and several possible causes for ineffective communication. A thorough analysis of each single case is required to identify the root cause. Monteiro de Carvalho (2013) does list one possible general cause; although the importance of communication is recognized, the formalized communication processes and practices are neither followed nor prioritized by project managers. High performing multi-cultural project teams on the other hand tend to have clearly defined communication procedures (Ochieng 2019). Cervone (2014) agrees that communicating in defined patterns helps to improve communication. Communication can be also impacted when different stakeholder groups use different jargon and language (Project Management Institute 2013). Every project should therefore have an agreed upon glossary of terms and acronym list and this should become an essential tool in project work (Mooz et al. 2004).

\section{Communication Channels in Global Project Teams}

When discussing about communication, it is not all about the content and information design, but also appropriate media or communication channel selection. While information design seeks to improve the effectiveness of information, communication design is concerned with the selection of media most suitable for carrying particular information to specific audiences or recipients (Fox and Grösser 2015). The most important communication methods to use during the execution of a project are written, oral and electronic communication, of which written and oral communication are regarded as the most effective communication methods (Zulch 2014a). Traditional communication channels don't neither satisfy nor follow the increasing requirements of global projects. Rapid technology development constantly introduces new possibilities and plays important role in development of communication process. Global projects are being increasingly managed through internet networks to increase efficiencies and facilitate communication and information distribution. Thanks to online collaborative toolsets, project-related material can be customized to stakeholder's role and function in the organization (Harley 2011). Social media are another suitable environment and communication channel for global projects and their usage is found to be increasing. Social media categories of document sharing, speed of exchange and wider coverage, irrespective of geographic location are found as most useful for team cohesion. Cohesion, coordination and relationship building within global teams are seen to be significantly enhanced by the use of social media tools (Kanagarajoo, Fulford, and Standing, 2019). The most frequently used of current 
digital media and social media tools for Eu projects are Facebook, Newsletter, Publications and LinkedIn (Pivec and Maček 2018). Due to rapid technology development, there are more and more communication channels available. Po, but it is very important that those are well-accepted by the stakeholders. If the media which is carrying the message is not acceptable to employees, it has low chance of being attended to or acted upon (Welch 2012). Some employees are still found to be relying on traditional channels, preferring e-mail, face-to-face communication, and telephone. Therefore, organizations may want to consider if and how to allocate resources for communication technologies. Although newer technologies hold great promise, resources may be better used in other areas if employees are not using those technologies (Snyder and Lee-Partridge 2013). Actual use of communication technology lags behind technical development and more could be done to encourage people to develop greater confidence on the suitability and dependability of the new technologies (Lee-Kelley and Sankey 2008). Successful project management with strong communication practice will change and evolve the organization (Johansen and Gillard 2005).

CULTURAL IMPACT ON INTERNAL COMMUNICATION

IN GLOBAL PROJECT TEAMS

Research into the cultural impact on multinational businesses was, and still is, the key to the success of global businesses (Zein 2012). Cultural issues can influence both positively and negatively the management of global project teams. There are several management challenges that require the adoption of certain ways of dealing with culture impacts to minimize potential problems in this context (Lima and Patah 2016). Distance between two countries can manifest itself along cultural, administrative, geographic, and economic dimension. Each dimension influences different businesses in different way. While geographic distance affects the costs of transportation and communication, cultural distance for example affects consumers' product preference (Ghemawat 2001). Economic situation of the country can also influence the cultural reaction to the project management deployment (Bredillet, Yatim, and Ruiz 2010). Cultural management needs to be included in the global project management spectrum as this will not only improve stakeholder resource management, but also the communication process. The literature of project management is light on the topic of managing stakeholders and there is little evidence of project managers learning from their colleagues in other disciplines (FitzPatrick 1997). Project managers 
traditionally have focus on efficiency and keeping the costs as low as possible, which has reflected into downplaying cultural and institutional diversity. This can often be pushed back on traditional project, but not in a global project (Ainamo et al., 2010). Anantatmula and Thomas (2008) see the global business environment and cultural values as two main driving factors that can be used as basis to build a successful project management effort in global projects. To be successful in managing resources across the globe, expectations for the team must consider the limitations of global project teams, including cultural differences and language barriers. How project managers manage these differences will determine the success of the global team as a whole (Browne et al. 2016).

\section{Cultural Management as Necessary Part of Global Project Management}

As already explained, people from different nationalities think differently about the relationship between the individual and the organization and have different perception of what an organization is, but a strong organizational culture can overcome barriers in a national culture (Hofstede 1983). Organizational culture has a significant influence on project performance and the long-term success of organizations (Yazici 2009). It is very important for people from other cultures to have more respect for the culture (especially organizational) of the country where they are located and work well with those leading their organizations, especially project managers, in order to contribute their best in team communication. Li agrees that foreigners should understand and respect local culture in order to mitigate culture risk. Appointing overseas project manager who is good at cross-culture management and has previous working experience in host country can also prove useful (Li 2009). The key to managing diversity is through cultural literacy and competency therefore project managers should take time to learn about different cultures (Obikunle 2002). Every global team should have at least some member who has prior distanced-working experience and can help other global members to deal with possible differences, tailored personal development programs and team-building exercises in order to raise cultural awareness and empathy (Lee-Kelley and Sankey 2008). Cross-cultural management is often regarded as a discipline of international management focusing on cultural encounters between what are perceived as well-defined and homogeneous entities and offering tools to handle cultural differences as sources of conflict or miscommunication, as Søderberg and Holden (2002) ex- 
plain. Same authors argue that this approach is out of phase with the business world of today, with its transnational companies that face the challenges of the management of global knowledge networks and multicultural project teams, interacting and collaborating across boundaries using global communication technologies. Effective use of cross-cultural project teams can provide a source of experience and innovative thinking to improve the likelihood of project success and enhance the competitive position of the organization. To achieve project goals and avoid cultural misunderstandings, project managers should be culturally sensitive and promote creativity and motivation through flexible leadership. Multicultural project management can succeed through culturally aware leadership, effective cross-cultural communication, mutual respect, and reconciliation (Anbari et al. 2009). Eriksson et al. (2002) agree that good leadership can resolve problems based on misunderstandings which are very common for global projects. Ochieng (2019) noted that effective project integration would have a positive effect on project success. The main categories for efficient integration process, central for project leaders and their project teams to appreciate and understand, are cross-cultural collectivism, cross-cultural empathy, crosscultural change, and cross-cultural uncertainty.

Each and every project, including global, requires a project team, which is the core element in project execution (Mossolly 2015). Going one step further, contemporary project management environment may require coordination and management of multiple teams, across multiple sites and even countries (Harley 2011). In contemporary environment, using global teams is a must for companies in order to take advantage of the knowhow and globally dispersed competencies, to assure time to market and provide better customer support (Eriksson et al. 2002). Effective management of globally dispersed project teams involves a complex set of variables which relate to the organizational structure, business process, managerial tools, and to the people in the organization and to the work itself. People issues have the strongest impact on project performance as they affect many of the secondary performance variables, such as work process and managerial tools. People are an intricate part of these subsystems, and issues affecting the people eventually impact the broader enterprise. Working seamless across borders and cultures requires more than just issuing work orders, project summary plans or management guidelines. It requires emphasis on common values and goals to focus and unify the team (Thamhain 2013). Zulch $(2014 \mathrm{~b})$ recommends a people-orientated approach towards project 
management, since the human element forms the project team. The project team becomes an open system as the human element continuously interacts with the external environment by receiving energy in and producing work out (Henrie 2014). The research on global projects shall always be associated with a clear link to global virtual team (Mossolly 2015).

\section{National Cultures and Their Specifics}

Each culture brings specific way of thinking and acting, a particular logic and a certain way of life. These factors become apparent by the time nations meet, as each party believes to behave in the one and only correct and right way. The tough work of a project manager entails coordinating all those 'right ways' to overcome the differences (Huang 2016). The classic approaches and methods of project management being used so far in most industrial applications were developed in the Western world (Huang and Chung 2014). The Western project management approach requires the use of not only its technology but also its values and beliefs (Wang and Liu 2007). This might work for traditional projects in Western world, but not for culturally dispersed global projects or even traditional projects outside Western world. Huang (2016) and several other researchers find significant differences between cultures in approach to project work.

Asian and Middle Eastern countries usually deliberately create opportunities to talk about business unofficially outside of the work environment. Asians like to use the indirect and extra-verbal communication to convey a message with the help of a specific location or gesture. The Chinese and East Indians prefer the project completion in phases to holistic approach. They are accustomed to react fast in the event of unforeseen situations. Chinese and Taiwanese have a tendency to be neglectful of accurate record keeping (Huang and Chung 2014). Mainga (2017) observed, after studying UAE construction industry, that project management in Middle East is based on hierarchy of roles. This hierarchical segregation often results in mistrust within the team and also results in the formation of divisive 'teams within teams' leading to a low productivity and lack of synergy due to power clashes and a continuous effort to bring down the other team. State-owned enterprises in UAE have the resources and willingness to recruit the 'best' project management talent/experts wherever they can find them across the globe. Three top factors that inhibit knowledge transfer across projects in UAE are high time pressures towards the end of the project, too much focus on short-term project deliverables and fear of negative sanctions when disclosing 
project mistakes. On the other hand, China is culturally a long way away from nearly everywhere. The many dialects of the Chinese language are notoriously difficult for foreigners to learn, and the local population's foreign-language skills are limited. Well-developed Chinese business culture based on personal connections, often summarized in the term guanxi, creates barriers to economic interchange with Westerners who focus on transactions rather than relationships (Ghemawat 2001). Chinese tend roughly to keep in mind the final goal and start the project in small steps. By the end of each project phase, they check the status and adapt the project plan. If necessary, even the project goal can be adjusted according to the happenings. The preliminary framework serves as a guideline, however it's not unchangeable. They may give the impression that they are lacking concentration and consistency however this is due to the difficulties to come to an agreement with all stakeholders. The advantage of the Chinese concept is a very fast reaction time. If necessary, Chinese can work non-stop - day and night - and they expect an authoritarian leadership. Periodical controlling, especially in the early stages, is necessary. The Chinese work philosophy is: 'All is well that ends well' (Huang 2016). In general, the Chinese traditional values/beliefs of strong hierarchy, family consciousness, and boss orientation are empirically major cultural barriers (Wang and Liu 2007).

Germans like direct and open communication (Huang and Chung 2014) and usually work out an entire complex concept with all the necessary details at the very beginning. After all participants accept the plan the project is completed methodically. Everybody knows exactly what to do and works autonomously. The schedule is treated very seriously and strictly observed, any plan modifications are not welcome. Some of the rare factors that might make plan modification possible are the quality issues. The German work philosophy is: 'Do the right thing from the start and it saves you trouble in the end' (Huang 2016). Middle and North Europeans usually talk about business at official occasions such as meeting. German and Swiss engineers are used to a holistic approach to project and work according to a plan. Europeans need longer time to react in the event of unforeseen situations in comparison to Asians. Correct record keeping is of utmost importance for the Germans and the Swiss (Huang and Chung 2014). Project managers from The Netherlands or Germany who are managing projects in the us, Canada, uk, Australia, or Sweden should be aware that their preferences for detailed analytic assessment at fixed time intervals is not appreciated in their host culture. They should adapt to the continuous verbal update practices via 
telephone to keep their project owner informed (Müller and Turner 2004).

Americans tend to define the central objective first, and then they decide whether to break it down into different steps or treat it as a complex entity. The reaction on an enquiry is quick and flexible. Americans keep the active lead and always follow the principle: 'Don't let it lie' (don't let it go cold). Customer requirements and wishes have high priority. However, uncontrolled changes or continuous growth in a project's scope is generally considered harmful. 'Scope creep' belongs to business. A well-executed risk management is expected. The American work philosophy is: 'Nothing is ever perfect. If nobody loses, everybody wins (Huang 2016). The situation in South America is quite different than in USA. Studying the process of managing global project teams in Brazilian multinationals, Rodrigues and Sbragia (2013) found that although the project managers recognize, even intuitively, that the cultural characteristics of individuals can affect performance, they are still incipient and rare the activities of planning and development of teams seeking to address the issue. The difficulties are worked in a style of trial and error, with little advance planning and a few actions effectively structured and systemic. Project managers from the us, Canada, or uk should change their communication behaviour when working in Japan or Brazil. The practice of verbal updates from their home culture is not appreciated in their host country. Personal communication at milestone or project end, as well as at fixed intervals is recommended for these countries (Müller and Turner 2004).

\section{Discussion}

In total 85 publications were included in this research. By far most of these, 71 , are articles, from which 45 were published in last decade. Further 22 were published in first decade of this century, meanwhile 4 are older. We also considered 3 books, 9 conference papers, 1 doctoral thesis and 1 master thesis. The full list of reviewed literature is presented in table 1.

\section{Conclusion}

The role of communication in project management is getting more important nowadays due to increasing trend of global projects and their specific requirements. Global projects can usually be described as high complexity projects and managing global projects using traditional project management approaches is difficult, or even impossible. In addition to those shared with traditional projects, global 
TABLE 1 List of Reviewed Literature

\begin{tabular}{|c|c|}
\hline Aarseth, Rolstadås, and Andersen (2013) & Lima and Patah (2016) \\
\hline Ahuja, Yang, and Shankar (2010) & Mainga (2017) \\
\hline Ainamo et al. (2010) & Men (2014) \\
\hline Molena and Rovai (2016) & Men and Yue (2019) \\
\hline Alami (2016) & Mooz et al. (2004) \\
\hline Allen, Lee and Tushman (1980) & Mossolly (2015) \\
\hline Alvarenga et al. (2019) & Müller and Turner (2004) \\
\hline Anantatmula and Thomas (2008) & Mohd and Noraini (2012) \\
\hline Anbari et al. (2009) & Monteiro de Carvalho (2013) \\
\hline Binder (2007) & Nishii and Ozbilgin (2007) \\
\hline Binder (2009) & Obikunle (2002) \\
\hline Bjorvatn and Wald (2018) & Ochieng, Edward G (2019) \\
\hline Bredillet, Yatim, and Ruiz (2010) & Oertig and Buergi (2006) \\
\hline Bristol and Yeatts (2010) & Parker, Kunde, and Zeppetella (2017) \\
\hline Browne et al. (2016) & Pivec and Maček (2018) \\
\hline Butt, Naaranoja, and Savolainen (2016) & Proctor and Doukakis (2003) \\
\hline Caldas and Gupta (2017) & Project Management Institute (2013) \\
\hline Chiocchio (2007) & Ramsing (2009) \\
\hline Collyer (2016) & $\operatorname{Ranf}(2010)$ \\
\hline Curtin and Jones (2001) & Rodrigues and Sbragia (2013) \\
\hline Dube and Katane (2017) & Rolstadås et al. (2014) \\
\hline Eriksson et al. (2002) & Ruck and Welch (2012) \\
\hline FitzPatrick (1997) & Sarhadi, Yousefi, and Zamani (2018) \\
\hline Fossum et al. (2019) & Shore and Cross (2005) \\
\hline Fox and Grösser (2015) & Snyder and Lee-Partridge (2013) \\
\hline Cervone (2014) & Søderberg and Holden (2002) \\
\hline Ghemawat (2001) & Stare (2011) \\
\hline Gray and Ulbrich (2017) & Söderlund (2004) \\
\hline Harley (2011) & Thamhain (2012) \\
\hline Henrie (2014) & Thamhain (2013) \\
\hline Henrie and Sousa-Poza (2005) & Tkalac Verčič, Verčič, \\
\hline Henttonen and Blomqvist (2005) & and Sriramesh (2012) \\
\hline Hofstede (1983) & Wang and Liu (2007) \\
\hline Huang, (2016) & Welch (2012) \\
\hline Huang and Chung (2014) & Welch and Jackson (2007) \\
\hline Jarvenpaa and Leidner (1999) & Winter et al. (2006) \\
\hline Johansen and Gillard (2005) & Yazici (2009) \\
\hline Kalyvas (2009) & Zajac (2012) \\
\hline Karanges et al. (2015) & Zajac (2013) \\
\hline Kerzner (2009) & Zein (2012) \\
\hline Kanagarajoo, Fulford, and Standing (2019) & Ziek and Anderson (2015) \\
\hline Lee-Kelley and Sankey (2008) & Zulch (2014) \\
\hline $\mathrm{Li}(2009)$ & Lima and Patah (2016) \\
\hline
\end{tabular}

projects have some unique characteristics, which need to be considered. The classic project management methods might not be the best 
fit for global projects, as there are significant differences between cultures in approach to project work. Moreover, traditional ways of communication don't meet the requirements of global projects, as they cannot fully answer the global project challenges such as distance, cultural diversity and language.

Several attributes distinguish global from traditional projects, among these some unique risks and success factors were observed. Among other political, economic and cultural risks, lack of mutual trust is recognized as one of the most severe risks on global projects. The most important success factors besides effective communication are project management competency, flexible leadership, change management and cultural management. Special requirements for global project manager were identified. Global project manager has to possess special abilities and skills, comparing to the requirements for the traditional project manager. Communication skills are the most important leadership attribute, while there are several additional requirements such as cultural and interpersonal awareness, networking ability and technological literacy, just to name few.

Communication is the function that integrates cost, scope and time to achieve quality. It has a fundamental function and is one of the cores, if not the key activity of every single project. Effective communication ensures effective change management, efficient stakeholder participation and is key condition to meet the project scope in required time, cost and quality. Successful project communication is only possible when the entire project team is communicating effectively. Good communication strategy must be defined, together with techniques, rules and templates to communicate effectively over a distance. Project management authority and distribution of formal power also play important role in effective communication. The most important communication methods to use during the execution of a project are written, oral and electronic communication. With rapid development of technology, global projects are being increasingly managed through internet networks and other modern communication channels, including social networks. Actual use of communication technology lags behind technical development.

Cultural issues can influence both positively and negatively the management of global project teams. Cross-cultural project teams can provide a source of experience and innovative thinking to improve the chances of project success. People issues have the strongest impact on project performance. To mitigate culture risk, foreigners should understand and respect local culture. Multicultural project management can succeed considering success factors such as cul- 
turally aware leadership, effective cross-cultural communication, mutual respect, and reconciliation. Organizational culture has a significant influence on project performance and can overcome the barriers of national culture. Cultural management has to be included in the toolbox of global project management.

The trend of project management research is on the rise, although the available literature continues to be limited. Findings and knowledge from other disciplines need to be woven into project management research to fill in the gaps and help build project managementspecific theories and research methods. Project manager must still look outside project management literature for information communication and culture topics and the implications these have toward project team success. The path towards multidisciplinary project management should be followed.

\section{Limitations}

Our literature review covered 87 quantitative and qualitative studies, each of them with its own specific limitations. Despite the best efforts to consider all of these within our research, this was not fully possible, thus the generalization of the findings is limited.

We mainly focused on internal communication between project core team members; communication with other project stakeholders was not investigated. This limitation includes both stakeholders outside and inside the organization, such as higher management and other company departments.

Only cultural impacts to internal communication were investigated, neglecting other impacts, such as political and economic impacts.

Communication is a complex research topic and our research only touched it from the perspective of global project management. Principles of communication which are mainly researched from other fields of science but might have an important impact on area under research were not considered.

Despite thorough investigation we allow the possibility that some contemporary study was not considered within our research and its findings were excluded.

\section{Future Research}

Internal communication in global project management is definitely an emerging topic and there are lots of gaps to be filled with further research on this field. Internal communication assessment is mostly 
focused on channels used, or volume of information generated. Process explanations are being investigated rather than the content of the communication itself, how well it is provided, or understanding. A changing communication environment calls for new approaches to assessment with an emphasis on communities, content and dialogue rather than volume and channels (Ruck and Welch 2012). Despite the acknowledged need to focus on communication as a whole in projects there is no indication in the literature that any collaboration exists between the field of corporate communication and the field of project management - creating a gap at the intersection of the two fields of research (Ramsing, 2009). Interdisciplinary research on multicultural and multilingual communication should be focused on both external and internal communication carried out in the international environment (Zajac 2012). The research on communication in global projects should be always linked to global virtual team, as people are the key ingredient of every single project team. Research needs to be combined with other relevant scientific disciplines, such as sociology, psychology and philosophy, and findings from these areas should be applied to project management.

National culture and its influence on the project management process have received little emphasis in the literature (Shore and Cross 2005). While research in project management has given adequate attention to improving efficiency of instrumental arrangements, the treatment or leveraging of cultural and institutional ingredients in projects has received less attention (Ainamo et al. 2010). Empirical-based project management research continues to be limited. Researchers will need to incorporate theories and concepts, developed in other disciplines, to build project management-specific culture-based theories and research methods. Literature reviews show a consistently low level of culture-specific literature within the leading project management journal publications. Project managers must look outside project management literature for information and guidance on culture and the implications it has toward project team success. To overcome the lack of available culture information within the areas surveyed, the project manager must expand his or her reading and learning to other culture-based discipline areas (Henrie and Sousa-Poza 2005). In global environments, it is necessary to have a more holistic view of the problems, since the sum of the parts is not necessarily equal to the whole. This raises the importance of engaging scholars, theorists and practitioners responsible for project management and their teams in a broader discussion that relates various disciplines of business administration and 
organizational theories, management and even people from other areas. Rodrigues and Sbragia (2013) suggest moving in multidisciplinary project management. Cultural impacts and their influence on project management should receive more emphasis in the literature, also merging the research with other scientific disciplines, such as ethnography, history and anthropology. Findings from these areas should be applied to project management research.

Nishii and Ozbilgin (2007) urge researchers to carefully describe the potential cultural boundedness of their research findings, and avoid (implicitly or explicitly) assuming that research findings from one culture will generalize to other cultural contexts. Since each culture has its own specifics, this brings a lot of challenge to generalize the findings of any research done on some specific case. Limitations have to be always emphasized and considered both in further research and in practice. The research on internal communication in global project teams fits better to qualitative paradigm, with case studies as suggested research method.

Project management research is in general still lacking the knowledge from other scientific disciplines and there are significant gaps in project management-specific theories and research methods observed. The aim should be to fill in these gaps, combining and merging project management with other relevant scientific disciplines.

\section{References}

Aarseth, W., A. Rolstadås, and B. Andersen. 2013. 'Managing Organizational Challenges in Global Projects.' International Journal of Managing Projects in Business 7 (1): 103-32.

Ahuja, V., J. Yang and R. Shankar. 2010. 'Iт-Enhanced Communication Protocols for Building Project Management.' Engineering, Construction and Architectural Management 17 (2): 159-79.

Ainamo, A., K. Artto, R. E. Levitt, R. J. Orr, W. R. Scott, and R. Tainio. 2010. 'Global Projects: Strategic Perspectives.' Scandinavian Journal of Management 26 (4): 343-51.

Akkermans, J., A. Keegan, M. Huemann, and C. Ringhofer. 2020. 'Crafting Project Managers' Careers: Integrating the Fields of Careers and Project Management.' Project Management Journal 51 (2): 135-53.

Alami, A. 2016. 'Global Project Management Challenges.' Pм World Journal 5 (1): 1-15.

Allen, T. J., D. M. Lee, and M. L. Tushman. 1980. 'R\&D Performance as a Function of Internal Communication, Project Management, and the Nature of the Work.' IEE Transactions on Engineering Management 27 (1): 2-12.

Alvarenga, J. C., R. R. Branco, A. L. A. Guedes, C. A. P. Soares, and W. da 
S. e. Silva. 2019. 'The Project Manager Core Competencies to Project Success.' International Journal of Managing Projects in Business 13 (2): 277-92.

Anantatmula, V. S., and M. Thomas. 2008. 'Global Projects: How To Manage Them Successfully?' Paper presented at PMI Research Conference: Defining the Future of Project Management, Warsaw, 13-16 July.

Anbari, F. T., Erzhen V. Khilkhanova, Maria V. Romanova, Mateo Ruggia, Han-Huei Tsay and Stuart A. Umpleby. 2009. 'Managing CrossCultural Differences in Projects.' Paper presented at PMI Global Congress, Orlando, FL, 10-13 October.

Binder, J. C. 2007. 'Global Project Management: Communication, Collaboration and Management across Borders.' Strategic Direction 25 (9).

Binder, J. C. 2009. 'The Global Project Management Framework: Communication, Collaboration, and Management across Borders.' Paper presented at PMI Global Congress 2009, Amsterdam, 18-20 May.

Bjorvatn, T., and A. Wald. 2018. 'Project Complexity and Team-Level Absorptive Capacity as Drivers of Project Management Performance.' International Journal of Project Management 36 (6): 876-88.

Bredillet, C., F. Yatim, and P. Ruiz. 2010. 'Project Management Deployment: The Role of Cultural Factors.' International Journal of Project Management 28:183-93.

Bristol, P., and G. Yeatts. 2010. 'Speak the Language of Leadership.' Paper presented at PMI Global Congress 2010, Washington, DC, 9-12 October.

Browne, W., S. Dreitlein, M. Ha, J. Manzoni, and A. Mere. 2016. 'Two Key Success Factors for Global Project Team Leadership: Communications and Human Resource Management.' Journal of Information Technology and Economic Development 7 (2): 40-8.

Butt, A., M. Naaranoja, and J. Savolainen. 2016. 'Project Change Stakeholder Communication.' International Journal of Project Management 34 (8): 1579-95.

Caldas, C., and A. Gupta. 2017. 'Critical Factors Impacting the Performance of Mega-Projects.' Engineering, Construction and Architectural Management 24 (6): 920-34.

Cervone, F. H. 2014. 'Effective Communication for Project Success.' oclc Systems \& Services 30 (2): 74-77.

Chen, T., F. Fu, R. Liu, X. Xu, S. Zhou, and B. Liu. 2019. 'How Do Project Management Competencies Change within the Project Management Career Model in Large Chinese Construction Companies?' International Journal of Project Management 37 (3): 485-500.

Chiocchio, F. 2007. 'Project Team Performance: A Study of Electronic Task and Coordination Communication.' Project Management Journal 38 (1): 97-109. 
Collyer, S. 2016. 'Culture, Communication, and Leadership for Projects in Dynamic Environments.' Project Management Journal 47 (6): 11125.

Curtin, T., and J. Jones. 2001. 'Communications Management for Difficult and Unpopular Projects.' Journal of Communication Management 5 (3): 277-86.

Dube, S., and J. Katane. 2017. 'The Influence of Organizational Culture and Project Management Maturity in Virtual Project Teams.' Paper presented at 2nd International Conference on the Internet, CyberSecurity and Information Systems, Johannesburg, 14-16 August.

Eriksson, M., J. Lilliesköld, N. Jonsson, and D. Novosel. 2002. 'How to Manage Complex, Multinational R\&D Projects Successfully.' Engineering Management Journal 14 (2): 53-6o.

FitzPatrick, L. 1997. 'Project Management and Communication Management - Two Growing Disciplines with Much to Offer Each Other.' Journal of Communication Management 2 (1): 59-69.

Fossum, K. R., J. C. Binder, T. Madsen, W. Aarseth, and B. Andersen. 2019. 'Success Factors in Global Project Management: A Study of Practices in Organizational Support and the Effects on Cost and Schedule.' International Journal of Managing Projects in Business 13 (1): 128-52.

Fox, S., and S. Grösser. 2015. 'Economical Information and Communication Design for Multi-National Projects.' International Journal of Managing Projects in Business 8 (3): 574-85.

Ghemawat, P. 2001. 'Distance Still Matters.' Harvard Business Review 79 (8): 137-47.

Gray, K., and F. Ulbrich. 2017. 'Ambiguity Acceptance and Translation Skills in the Project Management Literature.' International Journal of Managing Projects in Business 10 (2): 423-50.

Harley, J. 2011. 'Collaboration and the Use of Online Collaborative Toolsets in the Project Management Environment.' International Journal of Managing Projects in Business 4 (2): 345-54.

Henrie, M. E. 2014. Cultural Influences in Engineering Projects. New York: Momentum Press.

Henrie, M. E., and A. Sousa-Poza. 2005. 'Project Management: A Cultural Literary Review.' Project Management Journal 36 (2): 5-14.

Henttonen, K., and K. Blomqvist. 2005. 'Managing Distance in a Global Virtual Team: The Evolution of Trust through Technology-Mediated Relational Communication.' Strategic Change 14 (2): 107-19.

Hofstede, G. 1983. 'Cultural Dimensions for Project Management.' Project Management 1 (1): 41-8.

Holzmann, V., and L. Mazzini. 2020. 'Applying Project Management to Creative Industries: The Relationship between Leadership Style and Project Success.' Journal of Organizational Culture, Communications and Conflict 24 (1): 1-17. 
Huang, J. 2016. 'The Challenge of Multicultural Management in Global Projects.' Procedia: Social and Behavioral Sciences 226:75-81.

Huang, J., and A. Chung. 2014. 'Optimization of Global Project Management and the Required Tools.' Paper presented at IPMA Expert Seminar 2014, Zurich, 13-14 February.

Jarvenpaa, S. L., and D. E. Leidner. 1999. 'Communication and Trust in global Virtual Project Teams.' Organization Science 10 (6): 791-815.

Johansen, J., and S. Gillard. 2005. 'Information Resources Project Management Communication: Personal and Environmental Barriers.' Journal of Information Science 31 (2): 91-8.

Kalyvas, T. I. 2009. 'Effective Building and Management of Project Teams within the Multinational and Multicultural Environment of Alitalia s.p.a.' Master Thesis, University of Seattle.

Kanagarajoo, M. V., R. Fulford, and C. Standing. 2019. 'The Contribution of Social Media to Project Management.' International Journal of Productivity and Performance Management 69 (4): 834-72.

Karanges, E., K. Johnston, A. Beatson, and I. Lings. 2015. 'The Influence of Internal Communication on Employee Engagement: A Pilot Study.' Public Relations Review 41 (1): 129-31.

Kerzner, H. 2009. Project Management: A Systems Approach to Planning, Scheduling, and Controlling. Hoboken, NJ: Wiley.

Kerzner, H. 2019. Using the Project Management Maturity Model: Strategic Planning for Project Management. Hoboken, NJ: Wiley.

Kock, A., B. Schulz, J. Kopmann, and H. G. Gemünden. 2020. ‘Project Portfolio Management Information Systems' Positive Influence on Performance: The Importance of Process Maturity.' International Journal of Project Management 38 (4): 229-41.

Lee-Kelley, L., and T. Sankey. 2008. 'Global Virtual Teams for Value Creation and Project Success: A Case Study.' International Journal of Project Management 26 (1): 51-62.

Li, S. 2009. 'Risk Management for Overseas Development Projects.' International Business Research 2 (3): 193-6.

Lima, N., and L. A. Patah. 2016. 'Cultural Issue and its Influence in the Management of Global Project Teams.' Future Studies Research Journal 8 (1): 90-112.

Mainga, W. 2017. 'Examining Project Learning, Project Management Competencies, and Project Efficiency in Project-Based Firms (PBFS).' International Journal of Managing Projects in Business 10 (3): 454504 .

Men, L. R. 2014. 'Strategic Internal Communication: Transformational Leadership, Communication Channels, and Employee Satisfaction.' Management Communication Quarterly 28 (2): 264-84.

Men, L. R., and C. A. Yue. 2019. 'Creating a Positive Emotional Culture: Effect of Internal Communication and Impact on Employee Supportive Behaviors.' Public Relations Review 45 (3). https://doi.org/10 
$.1016 /$ j.pubrev.2019.03.001

Molena, A., and R. L. Rovai. 2016. 'Reference Model for Improved Communicability in Projects.' International Journal of Managing Projects in Business 9 (3): 682-706.

Mooz, H., K. Forsberg, H. Cotterman, and J. T. Whalen. 2004. 'Communicating Project Management.' Insight 6 (2).

Mossolly, M. 2015. 'Global Projects: A Conceptual Review on Execution Attitude in Multinational Corporations.' Procedia: Social and Behavioral Sciences 194:125-33.

Mohd, Y., and B. Noraini. 2012. 'Communications and Trust Is a Key Factor to Success in Virtual Teams Collaborations.' International Journal of Business and Technopreneurship 2 (3): 399-413.

Monteiro de Carvalho, M. 2013. 'An Investigation of the Role of Communication in iт Projects.' International Journal of Operations \& Production Management 34 (1): 36-64.

Müller, R., and J. R. Turner. 2004. 'Cultural Differences in Project Owner-Manager Communication.' Paper presented at PMI Research Conference: Innovations, London, 11-14 July.

Nishii, L. H., and M. F. Ozbilgin. 2007. 'Global Diversity Management: Towards a Conceptual Framework.' The International Journal of $\mathrm{Hu}$ man Resource Management 18 (11): 1883-94.

Obikunle, O. 2002. 'Dealing with Cultural Diversity in Project Management: A Dilemma in Communication.' Paper presented at PMI Annual Seminar \& Symposium, San Antonio, Tx, 7-8 October.

Ochieng, E. G. 2019. 'Framework for Managing Multi-Cultural Project Teams.' PhD dissertation, Loughborough University.

Oertig, M., and T. Buergi. 2006. 'The Challenges of managing CrossCultural Virtual Project Teams.' Team Performance Management 12 (1-2): 23-30.

Onwuegbuzie, A. J., and R. Frels. 2016. Seven Steps to a Comprehensive Literature Review: A Multimodal and Cultural Approach. Thousand Oaks, cA: Sage.

Onwuegbuzie, A. J., N. L. Leech, and K. M. T. Collins. 2012. 'Qualitative Analysis Techniques for the Review of the Literature.' The Qualitative Report 17 (28): 1-28.

Papadaki, M., N. Bakas, E. Ochieng, I. Karamitso, and R. Kirkham. 2019. ‘Big Data from Social Media and Scientific Literature Databases Reveals Relationships among Risk Management, Project Management and Project Success.' Pм World Journal 7 (8): 1-18.

Parker, D. W., R. Kunde, and L. Zeppetella. 2017. 'Exploring Communication in Project-Based Interventions.' International Journal of Productivity and Performance Management 66 (2): 146-79.

Peña, A. R., and F. A. Muñoz. 2020. 'Soft Skills as a Critical Success Factor in Project Management.' In Handbook of Research on Project Management Strategies and Tools for Organizational Success, edited 
by N. A. Moreno-Monsalve, H. M. Diez-Silva, F. N. Diaz-Piraquive, and R. I. Perez-Uribe, 376-92. Hershey, PA: IG I Global.

Pivec, M., and A. Maček. 2018. 'Employment Background Influence on Social Media Usage in the Field of European Project Management and Communication.' Journal of Business Research 94:280-89.

Proctor, T., and I. Doukakis. 2003. 'Change Management: The Role of Internal Communication and Employee Development.' Corporate Communications: An International Journal 8 (4): 268-77.

Project Management Institute. 2013. The High Cost of Low Performance: The Essential Role of Communications. Worcester, mA: Project Management Institute.

Ramsing, L. 2009. 'Project Communication in a Strategic Internal Perspective.' Corporate Communications: An International Journal 14 (3): 345-57.

Ranf, D. E. 2010. 'Cultural Differences in Project Management.' Annales Universitatis Apulensis Series Oeconomica 12 (2): 657-62.

Rodrigues, I., and R. Sbragia. 2013. 'The Cultural Challenges of Managing Global Project Teams: a Study of Brazilian Multinationals.' Journal of Technology Management \& Innovation 8:38-52.

Rolstadas, A., I. Tommelein, P. M. Schiefloe, and G. Ballard. 2014. 'Understanding Project Success through Analysis of Project Management Approach.' International Journal of Managing Projects in Business 7 (4): 638-60.

Ruck, K., and M. Welch. 2012. 'Valuing Internal Communication; Management and Employee Perspectives.' Public Relations Review 38 (2): 294-302.

Sarhadi, M., S. Yousefi, and A. Zamani. 2018. 'Participative Project Management as a Comprehensive Response to Postmodernism Criticisms: The Role of Communication.' International Journal of Managing Projects in Business 11 (4): 935-59.

Shirley, D. 2020. Project Management for Healthcare. Boca Raton, FL: Taylor \& Francis.

Shore, B., and B. J. Cross. 2005. 'Exploring the Role of National Culture in the Management of Large-Scale International Science Projects.' International Journal of Project Management 23 (1): 55-64.

Snyder, J., and J. E. Lee-Partridge. 2013. 'Understanding Communication Channel Choices in Team Knowledge Sharing.' Corporate Communications: An International Journal 18 (4): 417-41.

Souza, I., A. Tereso, and D. Mesquita. 2020. 'Communication in Project Management: An Action Research Approach in an Automotive Manufacturing Company.' In Trends and Innovations in Information Systems and Technologies: Worldcist 2020, edited by Á. Rocha, H. Adeli, L. Reis, S. Costanzo, I. Orovic, and F. Moreira, 64-73. Cham: Springer. Søderberg, A.-M., and N. Holden. 2002. 'Rethinking Cross-Cultural Management in a Globalizing Business World.' International Jour- 
nal of Cross Cultural Management 2 (1): 53-64.

Stare, A. 2011. 'The Impact of the Organizational Structure and Project Organizational Culture on Project Performance in Slovenian Enterprises.' Management: Journal of Contemporary Management Issues 16 (2): 1-22.

Söderlund, J. 2004. 'Building Theories of Project Management: Past Research, Questions for the Future.' International Journal of Project Management 22 (3): 183-91.

Thamhain, H. J. 2012. 'The Changing Role of Team Leadership in Multinational Project Environments.' Revista de Gestão e Projetos 3 (2): $4-38$.

Thamhain, H. J. 2013. 'Changing Dynamics of Team Leadership in Global Project Environments.' American Journal of Industrial and Business Management 3 (2): 146-56.

Tkalac Verčič, A., D. Verčič, and K. Sriramesh. 2012. 'Internal Communication: Definition, Parameters, and the Future.' Public Relations Review 38 (2): 223-30.

Wang, X., and L. Liu. 2007. 'Cultural Barriers to the Use of Western Project Management in Chinese Enterprises: Some Empirical Evidence from Yunnan Province.' Project Management Journal 38 (3): 61-73.

Welch, M. 2012. 'Appropriateness and Acceptability: Employee perspectives of internal Communication.' Public Relations Review 38 (2): 246-54.

Welch, M., and P. R. Jackson. 2007. 'Rethinking Internal Communication: A Stakeholder Approach.' Corporate Communications 12 (2): 177-98.

Winter, M., C. Smith, P. W. G. Morris, and S. Cicmil. 2006. 'Directions for Future Research in Project Management: The Main Findings of a Uк Government-Funded Research Network.' International Journal of Project Management 24 (8): 638-49.

Yazici, H. J. 2009. 'The Role of Project Management Maturity and Organisational Culture in Perceived Performance.' Project Management Journal 40 (3): 14-33.

Zajac, J. 2012. 'Towards Successful Communication in Global Virtual Teams: Team Language and Team Culture.' Kwartalnik neofilologiczny 59 (3): 345-70.

Zajac, J. 2013. Communication in Global Corporations: Successful Project Management via Email. Bern: Peter Lang.

Zein, O. 2012. 'Cultural Complexities in Multinational Projects.' Paper presented at PMI Global Congress, Marseille, 7-9 May.

Ziek, P., and J. D. Anderson. 2015. 'Communication, Dialogue and Project Management.' International Journal of Managing Projects in Business 8 (4): 788-803. 
Martin Bizjak and Armand Faganel

Zulch, B. 2014a. 'Communication: The Foundation of Project Management.' Procedia: Technology 16:1000-9.

Zulch, B. 2014b. 'Leadership Communication in Project Management.' Procedia: Social and Behavioral Sciences 119:172-81. 